\title{
Aktive leben länger
}

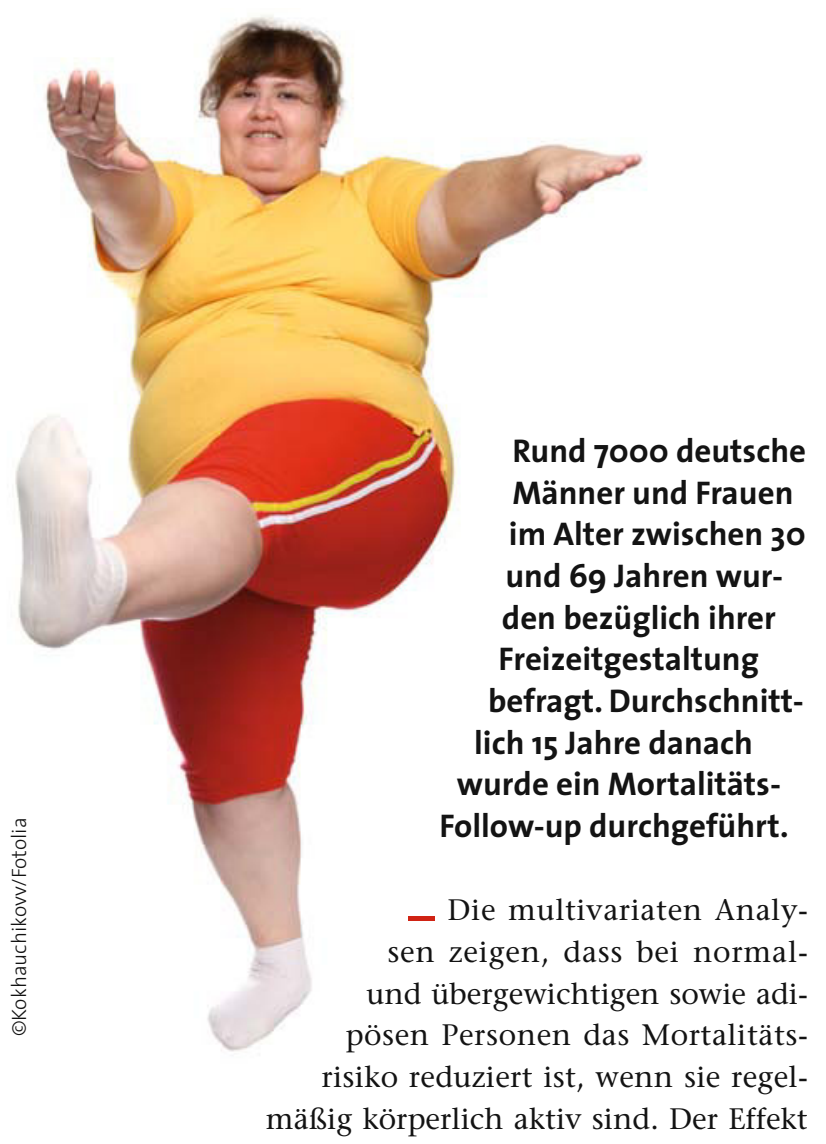
ist bei Frauen stärker ausgeprägt als bei Männern.

Die Autoren ziehen den Schluss, dass das Befolgen der gängigen Aktivitätsempfehlungen das Risiko, frühzeitig zu versterben, reduziert. Vor allem Übergewichtigen sollte daher primär eine Steigerung der Aktivität und erst sekundär eine Gewichtsreduktion empfohlen werden.

\section{Kommentar}

Mir scheint, als seien die Faktoren Aktivität und Gewicht nur schwer zu trennen. Weniger Gewicht erleichert die körperliche Aktivität, die wiederum das Gewicht reduziert. Ob daher primär weniger Kalorienzufuhr oder mehr Kalorienverbrauch anzuraten ist, ist kaum zu sagen. Idealerweise sollten wohl beide Strategien Hand in Hand gehen. Die vorliegenden Daten zeigen in beeindruckender Weise, wie umfassend die Effekte regelmäßiger körperlicher Aktivität sein können. Die Effektgrößen sind klinisch hochrelevant, und ich bezweifle, ob es eine andere Maßnahme gibt, die das Gesamtsterblichkeitsrisiko so drastisch, nebenwirkungsarm und kostengünstig beeinflusst.

- J. Bucksch, W. Schlicht

Reduziert sich das Mortalitätsrisiko sowohl für normal- als auch übergewichtige Personen durch körperliche Aktivität? Is mortality reduced by physical activity in normal- and overweight men and women? Dtsch. Z. Sportmed. 61 (2010) 72-78 